\title{
Uma conversa com Paul Standish sobre os trail-effects da psicologia e a "cultura da auditoria” na educação
}

\author{
Cristiane Maria Cornelia Gottschalk'
}

\section{Resumo}

Em tempos tão sombrios para a pesquisa educacional em várias partes do mundo, em que educadores e pesquisadores estão submetidos a uma cultura de auditoria cada vez mais implacável, tivemos o privilégio de entrevistar um dos poucos filósofos que, de uma perspectiva filosófica, questionam esse tipo de gestão educacional: Paul Standish, professor e diretor do Centro de Filosofia da Educação do Instituto de Educação da Universidade de Londres (University College London Institution of Education). Uma de suas principais críticas incide sobre o transporte abusivo de procedimentos contábeis, característicos do campo da administração, para a proposição de políticas educacionais que visariam a uma equivalente "transparência contábil". Recorre a filósofos como Wittgenstein e Austin, entre outros, para desconstruir o mito da transparência da prestação de contas no campo da educação quando são adotadas medidas avaliativas e de gestão pretensamente objetivas e eficientes, mas que, na verdade, têm tido como resultado a imposição de modelos empíricos de comportamento e de pensamento extremamente reducionistas e dogmáticos. Segundo ele, boa parte desses modelos é oriunda da psicologia, a qual, mesmo tendo alterado substancialmente seus aparatos teóricos como também suas práticas ao longo das últimas décadas, trouxe crenças iniciais que deixaram o que Paul Standish denomina de trail-effects" no imaginário do senso comum, os quais agem sub-repticiamente na base da cultura de auditoria que vem se instaurando no campo da educação. Ao longo da entrevista, Standish também aborda questões relativas ao lugar da filosofia analítica na educação, com suas diferentes vertentes; questiona o modo como o pós-estruturalismo tem sido apropriado pela pesquisa educacional; critica o uso da expressão ciência da educação, quando se desconsidera o fato de que as questões mais fundamentais da educação não podem ser resolvidas empiricamente; reflete sobre a formação do professor e as diferentes maneiras de se transmitir conhecimento; e enfatiza a importância e a fecundidade das ideias de Wittgenstein tendo em vista

I- Universidade de São Paulo, São Paulo, SP, Brasil

Contato: crisgott@usp.br

* Mantivemos o termo original traileffects para designar os vestígios ou marcas deixadas em uma trilha, traços de uma ocorrência que se reproduzem ao longo do tempo. esclarecer as confusões filosóficas em que nos enredamos quando a linguagem "entra em férias".

\section{Palavras-chave}

Filosofia da educação - Avaliação escolar - Gestão educacional Teoria e prática educacionais - Wittgenstein. 


\title{
A conversation with Paul Standish about the trail-effects of psychology and the audit culture in education
}

\author{
Cristiane Maria Cornelia Gottschalk!
}

\begin{abstract}
In times so grim for educational research in various parts of the world, where educators and researchers are subjected to an increasingly ruthless audit culture, we have had the privilege of interviewing one of the few philosophers who question this type of educational management from a philosophical perspective: Paul Standish, Professor and Head of the Centre for Philosophy of Education at University College London Institution of Education. One of his main criticisms focuses on the abusive transport of accounting procedures, characteristic of the field of administration, to proposing educational policies that supposedly aim at an equivalent accounting transparency. He refers to philosophers like Wittgenstein and Austin, among others, to deconstruct the myth of accounting transparency in education, when evaluative and management measures are adopted. Such supposedly objective and efficient measures have actually resulted in the imposition of empirical models of behaviour and thinking which are extremely reductionist and dogmatic. According to him, most of these models come from the field of psychology, which, despite having substantially changed its theoretical apparatus as well as its practices over the past few decades, has brought initial beliefs which have left trail-effects in the imaginary of common sense, acting surreptitiously on the basis of the audit culture that has established itself in the field of education. Throughout the interview, Standish also addresses issues relating to the place of analytic philosophy in education, with its various approaches, questions how post-structuralism has been appropriated by educational research, criticizes the use of the term science of education when one disregards the fact that the most fundamental issues of education cannot be resolved empirically, reflects on teacher education and the different ways of transmitting knowledge, and emphasizes the importance and fecundity of Wittgenstein's ideas aiming at the clarification of the philosophical confusions that we become entangled with when language "goes on vacation".
\end{abstract}

\section{Keywords}

I- Universidade de São Paulo, São Paulo, SP, Brasil

Contact: crisgott@usp.br
Philosophy of education - School evaluation - Educational administration - Educational theory and practice - Wittgenstein. 


\section{Apresentação}

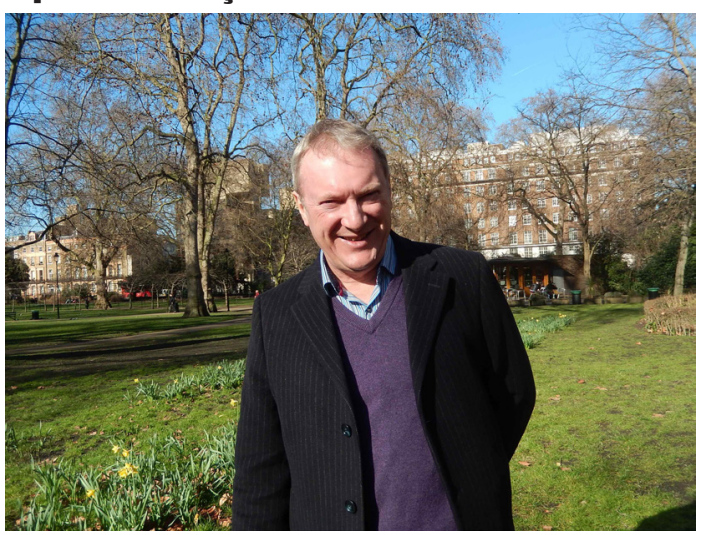

Fonte: arquivo pessoal do entrevistado

Paul Standish é professor e diretor do Centro de Filosofia da Educação do Instituto de Educação da Universidade de Londres (University College London Institution of Education). Suas áreas de maior interesse abrangem questões de ética e educação, democracia e cidadania, as novas tecnologias de informação e comunicação (TICs) e o ensino superior. Ao longo de sua extensa obra, tem discutido as relações entre a filosofia analítica e a filosofia continental, com foco nas tensões produtivas que são geradas ao longo do embate dessas vertentes filosóficas, tendo como referenciais teóricos centrais as ideias de Wittgenstein, Heidegger, Lyotard, Derrida, Scheffler, Levinas, Cavell, entre outros, transitando, assim, entre as filosofias da linguagem e da existência, com incursões também na filosofia política e no pós-estruturalismo.

Mais recentemente, Standish tem se ocupado em desvendar as relações entre a filosofia e as práticas educacionais. Em sua obra Beyond the self: Wittgenstein, Heidegger and the limits of language (1992), o filósofo explora as concepções divergentes sobre os limites da linguagem, traçando paralelos entre os dois grandes filósofos da área do século passado, Wittgenstein e Heidegger, tendo em vista uma crítica ao positivismo que ainda prevalece na linguagem do planejamento curricular e na elaboração de políticas públicas na educação.
Essa crítica foi retomada em um artigo mais recente, "Concepciones rivales de la Filosofía de la Educación" (2007), em que apresenta exemplos de como a filosofia da educação pode incidir na política e nas práticas educativas, esclarecendo equívocos e apontando novos rumos. Segundo Standish, grande parte da política educativa das últimas décadas inclinou-se fortemente em direção ao desenvolvimento de habilidades e competências, em detrimento da aquisição de conhecimento e compreensão. Sua hipótese é a de que essa nova linguagem das habilidades é um sintoma de uma nova forma de behaviorismo, profundamente em desacordo com os aspectos mais significativos da obra educativa. Propõe, então, como meta filosófica, explicitar a natureza dessa conexão com o behaviorismo e o tipo de metafísica nela pressuposto (STANDISH, 2007).

Standish esteve em setembro do ano passado pela primeira vez no Brasil, a convite da recém-criada Sociedade Brasileira de Filosofia da Educação. Aproveitando sua passagem pelos trópicos, a área de Filosofia e Educação da Pós-Graduação da Faculdade de Educação da USP convidou-o a apresentar uma palestra. Tendo como tema o estado da arte da filosofia da educação, o pesquisador surpreendentemente nos remeteu às origens da filosofia, aos seus legados mais ilustres, como os de Platão, Aristóteles e Heráclito, com suas diferentes perspectivas teóricas, tecendo relações inusitadas entre eles e apresentando, por fım, sua própria concepção de filosofia da educação: uma forma de investigação com fronteiras porosas, mas fundamentalmente ligada às questões de valores, que não podem ser evitadas no campo da prática educacional e que tampouco são passíveis de investigação empírica. Basta que o professor na sala de aula ou o gestor de políticas educacionais seja confrontado com problemas e tenha que lidar com eles em profundidade para que se deparem necessariamente com questões filosóficas.

No dia seguinte à palestra, Standish concedeu esta entrevista ao grupo de pesquisa 
Filosofia, Educação, Linguagem e Pragmática $(\mathrm{FELP})^{1}$, que recentemente traduziu o artigo “THIS is produced by a brain-process!': Wittgenstein, transparency and psychology today"2 (STANDISH, 2012), no qual ele discute, a partir de uma perspectiva wittgensteiniana, questões de avaliação educacional, em particular quando esta ocorre numa cultura de auditoria. A entrevista foi realizada com a participação de alguns membros do grupo - dentre os quais gostaria de agradecer especialmente a meus então orientandos Isabel Villalobos Hrdlicka e Rafael Ferreira de Souza Mendes Pereira -, e contou também com a presença de dois professores pesquisadores da Universidade Estadual de Campinas (Unicamp): o filósofo Arley Ramos Moreno (Instituto de Filosofia e Ciências Humanas), coordenador do grupo de pesquisa Filosofia da Linguagem e do Conhecimento, e o linguista e teórico da tradução Paulo de Oliveira (Centro de Ensino de Línguas).

0 interesse do grupo por esse texto de Standish deu-se, entre outras razões, pelo fato de estarmos vivendo no Brasil a adoção generalizada de exames padronizados para avaliar todos os níveis de ensino, gerando rankings de escolas e diretrizes educacionais fundamentadas nesses resultados. Em particular, o Exame Nacional do Ensino Médio (ENEM) passou a servir não só como instrumento de entrada para todas as universidades federais, mas também como modelo de currículo para todo o ensino médio no país, induzindo mudanças curriculares e alterações nos livros didáticos fornecidos pelo governo a todo o sistema público de ensino, com base numa matriz de competências e habilidades fundamentada em teorias das ciências cognitivas (AZANHA, 2006a, GOTTSCHALK,

1- Este grupo de pesquisa, que coordeno desde 2004 na Faculdade de Educação da Universidade de São Paulo (FEUSP), é cadastrado no diretório de grupos de pesquisas do CNPq e tem como referencial teórico central as ideias da segunda fase do pensamento do filósofo austríaco Ludwig Wittgenstein

2- Título traduzido para "'ISTO é produzido por um processo cerebral!': Wittgenstein, transparência e psicologia hoje", previsto para publicação em futura coletânea de textos do grupo FELP.
2012). A reflexão de Standish a respeito d os trail-effects da psicologia sobre as politicas educacionais de avaliação e as suas implicações nas práticas pedagógicas fez com que boa parte das questões endereçadas a ele fosse no sentido de esclarecer alguns aspectos de sua crítica à cultura de auditoria já entranhada em nossas práticas pedagógicas.

Como se verá ao longo da entrevista, Standish considera que há um transporte abusivo de procedimentos contábeis, característicos do campo da administração, para a proposição de políticas educacionais que visariam a uma equivalente "transparência contábil". Sua crítica é extremamente esclarecedora não só por possibilitar a desnaturalização de determinadas crenças, mas também por nos instigar a pensar outros modos de enfrentar os desafios do ensino e da aprendizagem, para além dos modelos reducionistas da tarefa educativa que têm assolado nosso país nas últimas décadas. De modo original, Standish recorre à concepção de linguagem de Wittgenstein (1997, 1998) para desvelar mecanismos obscuros que operam a partir de áreas como as da psicologia e de algumas ciências cognitivas e que deixam rastros no senso comum, gerando patologias do pensamento com consequências nefastas nos mais diversos campos do conhecimento. Assim, dessa perspectiva wittgensteiniana, chega à conclusão de que a necessidade dessas áreas de terem acesso a um conhecimento oculto, que estaria além de nossas práticas cotidianas fundamentadas apenas na confiança humana, transformou a economia ordinária de nossas vidas em uma "economia do conhecimento", na qual o conhecimento passa a ter o estatuto de mercadoria, tendo-se como finalidade tornar nossas práticas mais explícitas e supostamente mais passiveis de prestação de contas do que nossa linguagem ordinária permite.

De fato, estamos presenciando essa transformação não só no Brasil, mas também em diversos outros países, com práticas educacionais tais como as de avaliação do aprendizado escolar, que têm intensificado a 
produção de testes para verificar se os resultados de aprendizado pretendidos foram alcançados, com a ilusão de se ter encontrado um sistema de inspeção que possa substituir as avaliações que se baseiam na experiência acumulada do professor e no julgamento fundado em sua autoridade. Como já observava José Mário Pires Azanha em meados da década de noventa (AZANHA, 2006b), a avaliação "ganhou agora um vulto tão exagerado que talvez não seja exorbitante afirmar que muito do que se faz ou se tenta fazer nas escolas, de um modo geral, e nas universidades, de um modo muito especial, é feito com a preocupação quase neurótica e o temor angustiante de futuras avaliações". Tal previsão tem se confirmado em várias partes do mundo e tomado proporções alarmantes. Para atender as exigências dessa nova onda avaliativa regida por uma cultura de auditoria, o professor se torna algo muito próximo de um operador técnico flexível e, portanto, substituível, enquanto que as práticas anteriores vão sendo cada vez mais desconsideradas. Imagina-se, assim, ter-se encontrado maior rigor e transparência em avaliações fundamentadas em dados, transformação que, segundo Standish, já teria ocorrido nos sistemas de avaliação no Reino Unido. E o pior de tudo, ressalta ele, é que os próprios estudantes passam a acreditar que a tarefa da educação seria o alcance de metas no interior desse sistema mecanizado. Standish lembra que crianças com oito anos de idade já se preocupam agora em saber se cumpriram os critérios para uma lição dada ou se satisfizeram seus "objetivos de aprendizagem", atitudes inimagináveis nas gerações anteriores.

Enfim, a palavra de ordem nesta nova cultura educacional passa a ser transparência: deve-se prestar contas e, para isso, criam-se técnicas especiais aplicadas ao mundo da escola, o que tem como resultado a negação de suas práticas anteriores e impede a possibilidade de se avançar em questões que envolvem prioritariamente confiança e competências profissionais. No mundo globalizado, há uma tendência ao planejamento central orientado por indicadores de desempenho, a partir dos quais se prevê punições e recompensas, alimentando-se a desconfiança mútua e instaurando-se, assim, uma cultura da suspeita. Isso não significa de modo algum que Standish seja contrário à aplicação de exames padronizados, como esclarece ao longo da entrevista concedida. São alguns de seus aspectos por ele criticados que levam a essa espécie de cultura em que tudo é quantificado e automatizado. Tais trail-effects deixam de lado temas fundamentais, abordados durante a entrevista, como a importância de ter diferentes estilos de ensino, de resgatar a nossa tradição filosófica de mais de 2.000 anos para olhar de outro modo os problemas educacionais contemporâneos e, com o auxílio de filósofos como Wittgenstein e Heidegger, entre outros, percebermos que os grandes problemas da educação são essencialmente problemas filosóficos. 


\section{Referências}

AZANHA, José Mário Pires. A pedagogia das competências e o ENEM. In: AZANHA, José Mário Pires. A formação do professor e outros escritos. São Paulo: Senac, 2006a.

AZANHA, José Mário Pires. Avaliação escolar: algumas questões conceituais. In: AZANHA, José Mário Pires. A formação do professor e outros escritos. São Paulo: Senac, 2006b.

GOTTSCHALK, Cristiane Maria Cornelia. A natureza dos fundamentos do conhecimento em Wittgenstein - e suas implicações em processos de avaliação escolar. In: SILVA, João Carlos Pires da (Org). Certeza. Salvador: Quarteto, 2012. p. 71-84.

STANDISH, Paul. Beyond the self: Wittgenstein, Heidegger and the limits of language. Tokyo: Hosei University Press, 2012.

STANDISH, Paul. Concepciones rivales de la filosofía de la educación. Encounters on Education, v. 8, p. 17-27, Fall 2007.

STANDISH, Paul. "THIS is produced by a brain-process!": Wittgenstein, transparency and psychology today. Journal of Philosophy of Education, v. 46, n. 1, p. 60-72, Feb 2012.

WITTGENSTEIN. Ludwig. Philosophical investigations/philosophishe untersuchungen. Translated by Gertrude Elisabeth Margaret Anscombe. Oxford: Blackwell, 1997.

WITTGENSTEIN. Ludwig. Remarks on the philosophy of psychology. In: ANSCOMBE, Gertrude Elisabeth Margaret; WRIGHT, Georg Henrik von (Org.). Bemerkungen über die philosophie der psychologie. Oxford: Basil Blackwell, 1998. 


\section{Entrevista}

Primeiramente, gostaria de agradecer imensamente por sua disposição de mudar seu itinerário de viagem, atendendo ao convite para a palestra de ontem ${ }^{3}$, e também por ainda ter encontrado tempo para uma conversa sobre sua investigação filosófica e seus desdobramentos na prática educacional. Tema complexo este das relações entre teoria e prática, sobretudo nestes tempos neoliberais em que as novas tecnologias educacionais se sobrepõem a toda reflexão de caráter mais teórico. Neste contexto que prioriza cada vez mais resultados imediatos e eficiência, qual seria o lugar da filosofia da educação e que tipo de questões ela deveria abordar?

Acho que a filosofia da educação deveria tratar de modo direto as questões sobre os valores que deveriam guiar a ação do sistema educacional. Portanto, quais são os objetivos da educação? Para que queremos escolas? Que tipos de conhecimento são mais importantes? Essas questões não podem ser resolvidas empiricamente. É claro que nós podemos descobrir o que as pessoas pensam sobre isso, mas nós podemos - e devemos - ir além. Podemos entrar nessa discussão para justificar o que nós estamos ou deveríamos estar fazendo, abordando diretamente questões sobre valores.

No final, não podemos evitar fazer isso, apesar das várias estratégias de que dispomos para enganarmos a nós mesmos e nos convencermos de que essas questões podem ser resolvidas por meios técnicos. Se não formos apenas instrumentos do sistema, iremos nos questionar por que estamos ensinando alunos deste e não daquele modo. Enfim, acredito que todo professor ou formulador de políticas educacionais irá se deparar com questões de

3- A convite da área de Filosofia e Educação do Programa de Pós-Graduação da Faculdade de Educação, Paul Standish ministrou a conferência em 15 de setembro de 2014 e concedeu esta entrevista no dia seguinte à conferência. 0 trabalho de transcrição e de revisão do material da entrevista contou com a participação de Melise Caroline Bragion, Oscar Kent Mahar e Nicolas Gunkel. justificativas, de valores, questões que não podem ser desconsideradas e que têm sido colocadas por filósofos ao longo dos séculos.

Como você vê a influência crescente do pós-estruturalismo e da teoria crítica na pesquisa educacional?

Bem, deixe-me ressaltar, antes de tudo, que há problemas na maneira como o pós-estruturalismo e a teoria crítica têm sido recebidos e compreendidos na pesquisa educacional e em outros campos principalmente no das ciências sociais -, e acho que essa questão é bastante complexa. Algumas vezes, escritores pós-estruturalistas - como Derrida, Lyotard, Foucault - têm sido rotulados com o selo do pós-modernismo, e isso se tornou uma vertente muito em voga, pelo menos nos últimos vinte anos. E normalmente esse modo de pensar é compreendido como envolvendo um certo compromisso com o relativismo, o ceticismo (nunca se pode de fato saber) e o subjetivismo (onde tudo cabe ao indivíduo, resumindo-se tudo a seu ponto de vista). Essas maneiras de pensar vêm sempre acompanhadas de um tipo de modismo. Então, por exemplo, muitos professores vão falar em "saber-poder", e vão continuar repetindo esse termo até que ele se torne um substituto para o pensamento, tornando-se um obstáculo para o pensamento reflexivo. E frequentemente, a meu ver, eles ouvem essas ideias de Derrida, Foucault e outros, e as enxertam sobre aspectos existentes de seu pensamento. 0 enxerto acontece com plantas: uma pessoa enxerta uma planta sobre a outra, alguém enxerta uma pera em uma macieira. 0 que estou dizendo é que esses acadêmicos retiram um pouco de Derrida, um pouco de Foucault, e os enxertam sobre seus próprios conceitos preconcebidos.

Isso significa que, muitas vezes, eles consideram esses autores como aliados nos seus projetos de desmascarar o poder. Naturalmente, costuma ser uma coisa boa desmascarar o poder, mas não é sobre isso que, acredito, Foucault, 
Derrida e Lyotard tratam fundamentalmente. Suas posições são muito mais complexas e eruditas. Então, há aqui uma grande distorção.

\section{E quanto à teoria crítica?}

Bem, conheço menos sobre a teoria crítica, mas creio que ela tem sido transformada numa pedagogia crítica, e talvez haja um pouco de Freire adaptado a ela também. Estou pensando em Henri Giroux, nos Estados Unidos. Defensores da pedagogia crítica estão geralmente em departamentos da educação (e provavelmente com um background sociológico), e acho que há uma tendência a enxertar frases da teoria crítica na nova sociologia do conhecimento e a acreditar que elas são a mesma coisa. Acredito que a teoria crítica fosse sobre algo mais profundo. Não se tratava simplesmente de desmascarar o poder, do modo que a pedagogia crítica tenta fazer. Acho que o termo pedagogia crítica também foi levemente inspirado pela Teologia da Libertação; há uma conexão ali, que está associada particularmente à América Latina.

Que potencial você vê na filosofia wittgensteiniana para o debate educacional de modo a contribuir, confrontar ou complementar outras abordagens?

Se olharmos para Wittgenstein e aceitarmos o radicalismo do movimento dos seus primeiros escritos para os posteriores, o que posso identificar é, em parte, um afastamento da sistematicidade. No Tractatus, ele tenta colocar tudo em ordem. Já em seu trabalho posterior, ele diz, de fato, que esse não é o modo como as coisas são: tudo são jogos de linguagem, diversidade, semelhanças de família, e não uma estrutura singular e unificada. É um grande passo que ele dá. A língua não é simplesmente uma ferramenta que usamos: é algo que nos permite pensar. Nossos pensamentos vêm da língua em que nos iniciamos. É apenas por termos sido iniciados naquela língua que conseguimos articular as coisas, ter pensamentos, e assim por diante. Não fosse isso, continuaríamos como animais. Portanto, nós nos formamos pelas palavras que conhecemos. E é isso que gostaria de enfatizar.

No seu artigo "Concepciones rivales de la filosofía de la educación”, você diz que a avaliação "requer um professor sensível e experiente, situado no interior da prática que é a matéria de discussão; um bom professor, que é atento às respostas dos alunos, que está constantemente avaliando o que está acontecendo no ensino". Mas como nós podemos saber se o professor é um bom professor, sensível e experiente, se o seu trabalho não é avaliado? Não é possível a avaliação do aprendizado das crianças ser uma ferramenta adicional para um plano nacional de educação, planejamento escolar e mesmo para a autocrítica do professor? E sobre o seu outro artigo, "Wittgenstein, transparência e psicologia hoje", essa transparência na prestação de contas não poderia ser útil de alguma forma para a educação?

Eu não disse que a avaliação é algo completamente incorreto; o que estou contestando é a avaliação através dos tipos de testes que o sistema utiliza. Esses modelos se baseiam em quantificações de uma forma ou de outra - 1 a 10, ou "excelente, muito bom, satisfatório, insatisfatório”, ou seja o que for -, e esse tipo de classificação, é claro, é sistematizado dessa forma, em parte, para alimentar computadores, para alimentar bancos de dados e planilhas, para facilitar os ranqueamentos das escolas ou professores ou o que quer que seja. Então, desconfio muito desses aspectos da avaliação.

Acho também que a avaliação reforça a ideia de que há um padrão comum com o qual estamos trabalhando. Agora, não acho que há um único padrão comum para o que compõe um bom ensino. Penso em professores que conheci que não vinham com muito preparo para dar aula, mas que foram inspiradores pela maneira 
como agiam; eles interagiam de forma muito vívida com os alunos e obtinham deles algumas reações notáveis.

Também posso pensar em outros professores, que não eram nada carismáticos, mas entravam na sala e trabalhavam silenciosamente por meio de exercícios que eram sensivelmente adaptados às necessidades dos alunos, em seus diferentes estágios. Eu teria os dois professores, vejo ambos como bons professores. Mas não há nenhuma escala comum para julgá-los: não há um conjunto único de critérios. Então, o que quero dizer é que talvez haja uma espécie de semelhança de família, para usar uma expressão de Wittgenstein: existem sobreposições de conexão aqui, mas não há uma única boa qualidade. Talvez esta expressão semelhanças de família possa nos ajudar a pensar sobre isso.

$\mathrm{Na}$ verdade, o ensino custa muito dinheiro. Normalmente, é dinheiro público e paga o salário de muitos professores. Claro que é apropriado que o Estado ou o empregador espere alguns padrões dessas pessoas, desses funcionários, mas o meu ponto é que existem também processos informais de avaliação. Se você trabalha em uma escola, você tem uma boa ideia de quem são os bons professores e quem são os maus professores. As avaliações externas provavelmente não revelarão nada de novo para você. Como você tem essa sensação de quem são os bons professores? Porque você gradualmente acumulou experiência, você já ouviu falar sobre o que outros professores fazem, você tem memórias de suas próprias experiências como estudante, e todas essas coisas constituem um sentido de quem são os bons professores e quem não é. Não estou dizendo que isso é totalmente confiável e, certamente, abre espaço para antigos preconceitos. É conveniente, portanto, que essas discussões estejam inseridas em um contexto. É interessante, por exemplo, que, de vez em quando, um grupo de professores assista a uma aula que está sendo ministrada por outra pessoa. Pode ser de uma outra escola, em um vídeo. E, então, eles discutem o que o professor está fazendo, como ele está fazendo, como as coisas poderiam ter sido feitas de maneira diferente. E isso não com o objetivo de dar uma nota de 1 a 10, mas com o intuito de refinar e moldar seus julgamentos, fazendo conexões, confrontando seus pontos de vista em relação aos outros, em uma espécie de conversa sobre o que eles observaram na aula, talvez em comparação com sua própria experiência. Então, acredito que atividades como essas possam ser usadas no desenvolvimento de pessoal, no desenvolvimento profissional. Algo assim pode fazer parte também da formação inicial de professores.

Não me oponho a avaliações externas de qualquer tipo, seja formalmente, através de um serviço de inspeção, ou mais informalmente, através de uma prática de avaliação de professores por pares, onde professores em postos similares assistem a uma aula, fazem alguns comentários sobre ela, e depois compartilham essas observações com o professor e até com outros funcionários. Esse tipo de processo me parece saudável.

Sei que há problemas relacionados à avaliação. Às vezes, você tem professores que são incompetentes e precisam ser tirados do sistema, caso não possam ser ajudados. Concordo que o coordenador, o diretor, alguém no sistema tenha o poder de intervir e observar a sala de aula. E no fim, se as coisas estiverem realmente ruins e não puderem ser reparadas, ele precisará se livrar do professor. Não acho que haja nada de errado nisso, desde que seja feito de forma justa, por mais dura que essa experiência possa ser. É desejável que mantenhamos os padrões, mas sou a favor de que isso seja feito de maneiras flexíveis e informais, com base na experiência e na compreensão comum, como descrevi acima.

\section{Haveria algum critério formal para julgar se um professor é competente?}

Há uma pequena história que Israel Sheffler - o excelente filósofo da educação 
de Harvard, que morreu no início deste ano conta em um livro que ele escreveu chamado Professores de minha juventude, no qual ele reflete sobre alguns dos professores que o influenciaram. E ele se lembra de um professor de álgebra de quando ele tinha, talvez, 17 anos ou algo assim. Aparentemente, esse professor costumava entrar na sala com uma expressão aborrecida, atribuía exercícios para todos os alunos - o que, acredito, eram exercícios individualizados ou para grupos de alunos - e, em seguida, ele ia para o canto da sala de aula fumar um cigarro - o que era possível naquela época - e ficava fazendo palavras cruzadas, ou algo possivelmente não relacionado ao que os alunos estavam fazendo. Os alunos seguiam trabalhando até o final da aula, quando, então, o professor recolhia tudo e levava para casa. Na aula seguinte, ele voltava e entregava-lhes os exercícios corrigidos. Sem dizer muitas palavras, ele entregava o próximo conjunto de exercícios para eles fazerem e voltava para suas palavras cruzadas. Mas os estudantes acabaram desenvolvendo um grande entusiasmo pela álgebra, porque o que acontecia era o seguinte: ele era sempre muito sensível ao escolher o exercício certo para cada aluno, o exercício que iria estimulá-los e direcioná-los para diferentes caminhos. Então, à sua própria maneira, perversa e estranha, ele tinha uma grande sintonia com aqueles alunos e muita sensibilidade. E ele encontrou nessa abordagem bastante enviesada uma maneira eficaz de levá-los adiante em seus estudos de álgebra e incentivá-los, por mais estranho que isso possa parecer.

Então, aqueles que querem conjuntos claros de critérios, pelos quais as pessoas devem ser julgadas, muitas vezes são pessoas que gostam de um modelo. E acho que há um resíduo de platonismo aqui... Não estou criticando Platão; estou criticando a ideia atribuída a Platão de que, enquanto a nossa realidade mundana é confusa, há um reino de formas perfeitas que é, em última análise, mais real e, por isso, sempre temos que buscar aquelas formas perfeitas. Não há nada de errado com quem aspira melhorar. Pelo contrário! 0 ponto aqui é a força que a ideia do modelo tem em nós, a sensação de que ele é mais plenamente real, seu menosprezo pelo mundo que realmente experienciamos: essas ideias assentadas podem se tornar fixações. 0 modo como o modelo de bom professor funciona, com base em um conjunto perfeito de critérios, opera de maneira semelhante. Somos assombrados pela ideia do modelo perfeito, de como as coisas devem ser, da natureza empobrecida de nossa própria condição: ele está sempre lá. Ele está sempre nos guiando de alguma forma e, às vezes, impondo uma grade através da qual vemos o mundo. Precisamos nos libertar da sua possessão sobre nós. Isso é parte do que Wittgenstein estava tentando fazer. Nada está escondido e há diversidade. Precisamos colocar as coisas ao lado uma da outra, fazer conexões, identificar diferenças e não procurar alguma essência por trás do que estamos vendo.

Você mencionou Scheffler. A abordagem analítica, por meio de seu método de esclarecimento conceitual, poderia ajudar a responder a perguntas sobre o que deve orientar a formulação de um currículo?

Eu ficaria contente se pudesse dizer que, ao perguntar às escolas "Será que devemos adicionar isso ou aquilo ao currículo?" ou "Quais conhecimentos são importantes?", eu estivesse sendo claro sobre os conceitos com os quais estou trabalhando. Mas a questão é mais complicada, porque, na metodologia e na própria concepção da abordagem analítica, por vezes, alguma coisa a mais está acontecendo. Não se trata apenas de ser razoavelmente claro; isso por si também recai em um pressuposto metafísico.

0 exemplo mais claro que conheço sobre isso, nos anglófonos, principalmente no mundo analítico, é o filósofo John Wilson, que trabalhou em Oxford por vários anos, mais ou menos da década de 1960 até os anos 2000. Ele morreu há cerca de dez anos. John escreveu muitos livros ou, diriam alguns, ele escreveu o mesmo livro muitas vezes! Ele acreditava que a única coisa 
que a filosofia deveria fazer era esclarecer a natureza dos conceitos que estamos usando. Se pudéssemos fazer isso, deveria resultar em um sistema educacional bem concebido.

Então ele analisava, por exemplo, um conceito como ensinar e mostrava que, onde há ensino, deve haver aprendizado também. Por exemplo, se eu entrar na sala de aula, falar por uma hora e sair, e então um colega perguntar para mim "O que você estava fazendo?", e eu disser "Estava ensinando a classe", mas os alunos saírem para tomar um café e afirmarem "Não aprendi nada, foi uma completa perda de tempo", então, na verdade, eu não os estava ensinando; eu estava falando, mas não estava ensinando. Assim, o conceito de ensino envolveria dois átomos, a saber: o átomo referente ao que eu digo ou apresento e o átomo relativo ao que os alunos aprendem.

Como já mencionei na analogia dos átomos, o modo como ele compreendia essa análise era como uma análise química, e ele pensava que, se ele passasse por esse processo com a gama de conceitos que são fundamentais para a educação (tais como aprendizado, ensino, doutrinação e a própria educação), todos esses conceitos centrais iriam se dividir em suas partes atômicas: então, teríamos uma base sólida para o sistema educacional.

Que teoria epistemológica oferece a base para essa concepção atômica de ensino e aprendizagem?

Acho que o pano de fundo para isso filosoficamente seria a Teoria das Descrições, de Bertrand Russell, que, simplificando, sustentou a ideia de que qualquer proposição ordinária, tal como, “o copo está sobre a mesa”, correlaciona-se, se ela for verdadeira, com um fato no mundo. Há uma coisa, uma xícara, e outra coisa, uma mesa, e uma terceira coisa, uma relação de estar em cima (ou seja, em cima de algo). Então, isso é uma espécie de estrutura molecular. Claro, não era tão simples assim, e Russell nunca se sentiu realmente capaz de identificar a base para tudo isso, mas a suposição metafísica é de que há uma realidade subjacente com a qual a língua tenta se correlacionar. Essa realidade está lá e, na visão de John Wilson, há uma verdadeira natureza da educação. Se alguém puder descobri-la ou revelá-la por meio de análise, então o nosso sistema educacional estará garantido.

Agora, em oposição a isso - dentro mesmo da filosofia analítica anglófona -, escreveu-se muito sobre a contestabilidade da essência. Há um artigo escrito por um homem chamado Gallie, em 1956, intitulado "Essentially contested concepts", em que ele diz que muitas coisas na nossa vida (como a educação, o ensino, a aprendizagem, a beleza, entre outras coisas) não podem ser reduzidas a uma essência do mesmo modo que se analisa a água como H20, porque essa essência vai ser sempre contestável. Haverá diferentes atitudes, pontos de vista, possibilidades e, se pensarmos no caso da educação, acredito que o que importa nela não é algo que irá algum dia ser estabelecido de forma definitiva. Trata-se de algo sobre o qual os seres humanos irão discutir continuamente. Sócrates se perguntava: "Como devo viver? Que tipo de vida devo viver?”. E essas são as perguntas que todos devemos fazer a nós mesmos. É por isso que, em certo sentido, a filosofia não faz nenhum progresso; não é como a ciência física. Não faz nenhum progresso, porque, como na religião, cada geração tem de fazer essas perguntas para si mesma. De certa maneira, todos nós temos individualmente que fazer essas perguntas para nós mesmos. Quando digo "perguntar para nós mesmos" não estou dizendo que tudo é apenas subjetivo, que é uma questão de gosto pessoal etc., porque, é claro, se fizermos essas perguntas de forma responsável, então iremos prestar atenção ao que está sendo dito pelos outros, principalmente por aqueles que já estudaram essas coisas a fundo, pelas tradições da filosofia que ultrapassam dois mil anos, e outras tradições de pensamento também.

Discordo fortemente de John Wilson. $\mathrm{Eu}$ poderia dar referências do que discuti com ele, mas o que quero dizer é que a filosofia 
da educação deve abordar essas questões, assim como Platão e Sócrates fizeram, assim como Rousseau fez e outros através de suas gerações. Assim como fazem muitos professores nas escolas. Devíamos tentar abordar essas questões e apresentar razões. Precisamos oferecer uma explicação de por que as escolas devem oferecer a aprendizagem liberal ou devem enfatizar a aprendizagem profissional. Diferentes argumentos são possíveis, e isso é precisamente o que temos que fazer se formos propor um sistema educacional razoável e melhorar o que temos.

Entre o método dos filósofos analíticos e a filosofia wittgensteiniana, há certamente a sugestão de uma conexão familiar. No entanto, apesar de alguns reconhecerem os primeiros como herdeiros do pensamento de Wittgenstein, pesquisadores como Paul Smeyers e J. D. Marshall alegam que a tradição analítica na filosofia da educação não estava à altura do desafio de sua filosofia, principalmente em sua segunda fase. Em sua opinião, quais são os principais aspectos da filosofia wittgensteiniana que não podem ser conciliados com a perspectiva analítica? E quais são as implicações dessa divergência para a filosofia da educação?

Considero essa questão extremamente complexa e vou responder por partes. Em primeiro lugar, a filosofia analítica pode se tornar apenas um jargão: algumas vezes, ela é usada demais e cobre uma vasta gama de filósofos. Um exemplo extremo de filósofo analítico da educação é John Wilson, que estava comprometido com uma análise quase química de conceitos. Nem todos os filósofos analíticos, no entanto, entendem deste modo o que estão fazendo. Assim, temos que pensar sobre o que se quer dizer com "filósofos analíticos" antes que isso possa ser respondido. Seria necessário ser mais específico sobre o que se está pensando: se sobre as correntes predominantes da filosofia ou sobre a filosofia da educação.
É verdade que, em determinado momento, Wittgenstein foi considerado uma figura-chave na filosofia analítica. E é claro que o Tractatus o qualifica como tal nessa filosofia. Mas, em sua obra posterior, ele se afasta bastante dela, separando-se de muitas de suas correntes principais.

Nas décadas de 1940 e 1950, o positivismo lógico era muito dominante, e o quanto Wittgenstein se distanciou dessa corrente não foi muito bem percebido. John Austin também se afastou bastante dela de diferentes modos.

No que diz respeito à filosofia analítica da educação, penso que aqueles que adotaram tal rótulo nunca estiveram fazendo apenas análise. De modo geral, não acredito que R. S. Peters e seus colegas, ou mesmo John Wilson, estavam realizando apenas uma análise conceitual, e certamente Scheffler estava fazendo algo a mais que isso. A metodologia oficial era analisar conceitos, mas eles acabaram propiciando uma rica contribuição à educação: expressaram uma visão da educação, inspirados, no caso de Peters e de seus colegas, por Michael Oakeshott, um inglês conservador e grande filósofo.

A crítica específica que Smeyers e Marshall fizeram a Peters é que ele e Paul Hirst teriam analisado a ideia de jogos de linguagem e sua variedade e dito: "Bem, a grade curricular - física, história, literatura, matemática - é constituída por diferentes jogos de linguagem, e isso vai ao encontro do que Wittgenstein está dizendo". Mas, na verdade, Wittgenstein quis dizer algo muito mais radical do que isso. Ele não estava pensando, digamos, na história como um jogo de linguagem: ele estava pensando em coisas como debater uma questão, ou fazer orações, ou contar uma piada. Em outras palavras, partes bem menores da linguagem em uso. Assim, eles distorceram o sentido da expressão jogo de linguagem. Eles sistematizaram demais uma contribuição de Wittgenstein e perderam parte daquilo com que ele estava preocupado. Então, concordo com Smeyers e Marshall sobre essa questão, embora eu não concorde integralmente com a opinião deles sobre Wittgenstein. 
Wittgenstein era diferente dos filósofos analíticos da educação que descrevi e diferente de muitos outros filósofos analíticos. Ao enfatizar a expressão seguir regras, ele está preocupado em mostrar que, enquanto há algumas regras que permanecem fixas - por exemplo, as regras do xadrez -, há outros tipos de regras em que não se determina toda a aplicação futura. Os conceitos que usamos, as palavras que usamos, são regidos por regras abertas que se modificam de maneiras imprevistas, e isso é absolutamente crucial para a ideia de cultura e para o que é ser um ser humano. Wittgenstein tinha uma hostilidade geral em relação ao intelectualismo, à teorização excessiva, e isso explica a sua maneira de superar o dualismo corpo mente, e sua concepção de aprendizagem no sentido de saber como seguir em frente. Também decorre disso a importância que ele dá ao ver como, a ver conexões, e à imaginação, na segunda parte das Investigações.

A imaginação é muito importante. Ela está muito forte em sua obra e no senso de ética que, creio eu, a permeia, sem que a ética se torne um tópico de tratamento sistemático e explícito. Ética tem muito a ver com nossa vida, perpassando o que fazemos. E, naturalmente, a ética também está em sua percepção de que a língua e as ações estão profunda e internamente relacionadas entre si. Não se trata de a língua ser apenas um instrumento para nosso uso. A ética está presente também em sua hostilidade em relação à teorização. Ele fala sobre o ensino no sentido de dar a alguém as dicas certas e treiná-lo para os julgamentos corretos: olhe para este exemplo, tente ver desta maneira, olhe para o quadro, preste atenção na figura à direita, veja como ele pode estar vendo as coisas e como isso afeta o jeito como você vê as coisas. Conduzidos dessa maneira, nós começamos gradualmente a ver as coisas com mais profundidade e com novas perspectivas.

Em seu texto "Wittgenstein, transparency and psychology today", você afırma que, do mesmo modo que a bruxaria fazia parte da base das explicações, hoje esse papel é ocupado pela psicologia do senso comum, juntamente com outros saberes, em que se considera o corpo separado da mente. Você dá como exemplo alguém respondendo uma pergunta se utilizando da seguinte expressão: aguarde um momento enquanto eu processo o que você me disse. Essa resposta indicaria que o interlocutor pressupõe um mundo mental anterior à linguagem ou ao que está sendo dito expresso pela linguagem. Como você mesmo observa, este interlocutor poderia apenas estar querendo dizer que necessita refletir mais sobre o assunto, mas o uso da expressão processar o que foi dito indicaria uma mitologia de base constituída pelos trail-effects de certos ramos da psicologia, que foram incorporados pelo senso comum. Minha questão é a seguinte: será que essa expressão estaria de fato pressupondo a existência de processos ocultos que devem ser desvelados ou essa interpretação viria apenas de um interlocutor da filosofia, por exemplo, de um filósofo mentalista? Retomando Wittgenstein, a linguagem ordinária está em ordem. Os problemas surgem quando se começa a fazer filosofia do que foi dito ou, no contexto educacional, quando um pedagogo ou um avaliador usa esse tipo de expressão pressupondo, sim, a existência de processos ocultos que devem ser desvelados. Ou seja, não seria a mitologia do senso comum que leva a confusões, mas sim o uso filosófico ou teórico que se faz de determinados fatos do cotidiano?

0 problema com o caso da pessoa que diz "Espere um momento enquanto processo isso" é bem sério. E, para entender por que isso é um problema, nós precisamos olhar para outros contextos nos quais a expressão processando é usada e ver as conotações que esses outros contextos têm. Em geral, são aqueles mesmos contextos de laboratório, com conotações científicas, que encontramos quando o processo pelo qual uma lagarta se transforma numa borboleta é descrito. Vemos diagramas em 
um livro de biologia: qual é o processo pelo qual alguma coisa é produzida por tais e tais componentes químicos, qual é o processo pelo qual nós digerimos proteínas, ou seja lá o que for? Penso que as conotações [dadas a esses processos] indicam que a pessoa que diz "Espere enquanto processo isso" está alinhando sua concepção de mente a algo científico.

A última coisa que quero dizer é relacionada ao segundo ponto que você tocou de alguma forma, que é sobre Frazer. Eu tenho uma certa inquietação a respeito desse tipo de discussão porque algumas vezes ela significa que Wittgenstein... Podemos dizer que Wittgenstein nos leva de volta ao cotidiano, ele quer trazer a linguagem "em férias" de volta para casa, e então nós teremos paz. E acho que aqui há um perigo em ler Wittgenstein: nós nos apegamos muito seguramente, muito rapidamente, muito fortemente à categoria do cotidiano, do ordinário. Quando começamos a fazer isso, acho que corremos o risco de essencializar o comum, no sentido mesmo de metafisicalizá-lo.

Realmente o comum é um tipo de categoria muito mais fluída. Há coisas que dizemos agora em nosso discurso do dia a dia, como, por exemplo: "Não comi muita gordura hoje, então posso comer outro biscoito. Eu não ingeri muito colesterol". Estamos tão cientes desse discurso nutricional agora - e acredito que a maior parte dele seja correto, pois provavelmente teremos maiores chances de ficar doentes se comermos muita comida gordurosa -, que provavelmente não é uma coisa ruim que se fale com tanta naturalidade sobre essas coisas, e se use essas palavras de uma maneira que as pessoas há cinquenta anos atrás não teriam feito.

Então, a nossa língua muda, assim como a categoria do cotidiano ou do ordinário em oposição ao técnico. Nós não devemos considerá-la como sendo muito precisa (clear). Mas, mesmo que não seja muito precisa (clear), não significa que não possa ser aplicada com bons resultados em casos específicos. Esse uso mais fluído e, talvez, menos consciente não envolve necessariamente uma metafisicalização da categoria.

No final desse mesmo artigo, você se pergunta se estaria fazendo o mesmo que Frazer ao julgar os rituais de certos povos como má ciência, quando você critica os trail-effects da psicologia no senso comum, por exemplo, a aceitação de uma ciência da felicidade, que poderia medir o quanto cada um é feliz. Mas, nesse caso da ciência da felicidade, em que essas mensurações e crenças correlatas fazem parte de um aparato teórico, não teria que ser vista como ciência? Em outras palavras, essas crenças têm a pretensão de ser científicas, enquanto que os rituais dos povos primitivos eram de outra natureza. Sua finalidade era de venerar os deuses, e não o de explicar ou descrever algo. Então, até que ponto de fato os trail-effects da psicologia fazem parte de nossas mitologias de base, exercendo essa função análoga à da bruxaria na Idade Média?

Acredito que poderíamos dizer que esse tipo de psicologia tem um efeito ruim; bruxaria no meio da Idade Média teve um efeito ruim, ao passo que as práticas religiosas primitivas que Frazer descreve eram parte da mitologia de base: elas não eram, segundo sua argumentação, perniciosas ou prejudiciais. Por exemplo, o caso da mulher bósnia que adota uma criança e depois, em um ritual, tira a criança de baixo de sua saia: não há nada de danoso nisso. Trata-se obviamente de um ritual, e Frazer foi obtuso ao não entender isso. Mas bruxaria é uma má ciência, e isso também parece refletir algo de profundamente ruim na sociedade. 0 que quero dizer com má ciência é que ela tem testes: considere o teste infame para bruxaria por si só (o teste que acaba por ser a mesma coisa que está condenando): a mulher é amarrada e imersa na água. Se ela não se afogar, ela deve ser uma bruxa, e então deverá ser morta. 
Mas a bruxaria também não faz parte de um ritual, assim como o exemplo da mulher bósnia?

Estou sugerindo que talvez muitas formas de magia do século XVII na Europa, por exemplo, tenham sido contaminadas com a ciência, no sentido da crítica de Wittgenstein. Quer dizer, ele é contra a adoção de práticas científicas em áreas nas quais elas não se aplicam, e parece que esse tipo de teste que nós acabamos de considerar tem pretensões científicas no sentido moderno. É diferente da mulher bósnia, penso eu: a retirada da criança de debaixo de sua saia é uma expressão de sua aceitação da criança. Acredito que talvez seja possível redescrever o afogamento da bruxa de maneira que ele se torne uma cerimônia de exorcismo pela qual a cultura expurga seus medos do mal pelo próprio mal. Mas uma espécie de linha de divisão pode ser traçada, e surge uma diferença.

Penso que pessoas que fazem psicologia hoje também têm essa crença profunda no que elas estão fazendo. Acho que isso pode fazer parte do que está acontecendo hoje; há essa crença profunda, como você sabe. Práticas de bruxaria no século XVII, primeiramente, $e$ aquelas práticas mais recentes em que ideias de realizar testes e agir deste ou daquele jeito de acordo com os resultados, em segundo lugar, são similares de algum modo em sua emulação de práticas científicas. Agora estou claramente tomando emprestada em parte a preocupação de Wittgenstein de termos sido enfeitiçados por algumas coisas que fizemos com a linguagem, e de não estarmos dispostos a nos libertar dessa feitiçaria. Frazer é enfeitiçado pela língua porque ele aborda as tribos primitivas com um padrão de entendimento, aquele do pastor inglês, como diz Wittgenstein com desdém, e ele não consegue ver o que está acontecendo. Mas quero dizer que alguns psicólogos estão enfeitiçados pela linguagem que estão usando e que isso é semelhante ao feitiço da própria bruxaria. 0 caso da mulher bósnia não é.
Então, não se poderia falar de uma ciência social ou mesmo de uma ciência da educação?

Aqui há um problema com a palavra ciência em inglês (talvez em português também haja, não tenho certeza). A primeira conotação que ciência tem é aquela do homem de jaleco branco em um laboratório. Estou dizendo homem intencionalmente. Essa é uma imagem poderosa e particular. E então, claro, as ciências sociais são derivadas desse uso e dessas associações. Ciência da educação, creio eu, já soa um pouco estranho. Se pensarmos em Wissenschaft, a expressão em alemão, já temos um conceito bem mais amplo. No início dos anos 1990, escrevi um texto chamado "Por que nós não deveríamos falar em ciência na educação" no livro editado por Jim Marshall e Paul Smeyers, mencionado na questão anterior. E foi um pouco constrangedor, porque Paul estava trabalhando em um departamento de ciências educacionais - a versão oficial inglesa de seu título em holandês. Podemos dizer também que, na linguagem dominante internacional da pesquisa educacional, ciência da educação se tornou um termo mais usual, mas me atenho à visão de que a expressão continua soando mal. E, ao pensar em mim como um cientista, isso soa mais absurdo ainda. Mas talvez os nomes não sejam tão importantes. 0 que sou contra é a essa pretensão científica de algumas pesquisas educacionais. Acho que a sociologia mais interessante, por exemplo, tende a ser mais discursiva e menos obcecada por dados. É claro que nós precisamos de dados para saber algumas coisas - a relação entre pobreza e progresso educacional, por exemplo - e, então, sim, nós deveríamos descobrir quantas pessoas pobres existem etc. Defendo fortemente esse tipo de pesquisa empírica, mas acho que a obsessão por coleta de dados ou evidências é profundamente danosa na ciência social de maneira geral e na pesquisa educacional em particular. 
Você poderia falar mais sobre essa cultura de transparência? Qual é mais precisamente sua crítica a ela?

É claro que, quando você lida com pessoas, você espera que elas sejam honestas com você. Quando você lida com dinheiro, você quer saber exatamente o que está acontecendo com ele. Mas a transparência pode tornar-se um problema, pelo menos na educação, porque, em algumas culturas de hoje (caso do Reino Unido), existe a visão de que um aluno deve saber tudo sobre um curso antes de se matricular nele. Então, ele precisa saber com antecedência quais serão os resultados obtidos, o que ele aprenderá no decorrer do curso e até mesmo como ele será avaliado. Agora, a minha sensação é de que isso não é uma coisa boa. Se eu comprar um carro, quero saber exatamente o que ele vai fazer, mas a educação é o caso em que dificilmente você terá como entender sobre o que é um tópico ou o que um assunto engloba até que você seja apresentado a ele. Leva mais tempo para que o quadro todo ganhe contornos.

Se insistirmos que tudo deve ser transparente desde o início, estaremos reduzindo a substância do que nós ensinamos. 0 aluno será, em certo sentido, confinado ao que já sabe, limitado aos horizontes que já conhece. E, variando a metáfora, o aluno irá perder a possibilidade do engajamento e do entendimento mais profundos aos quais poderia ser iniciado.

Em que sentido a cultura da auditoria está relacionada com a performatividade?

Performatividade é uma palavra cunhada por Jean-François Lyotard em seu livro $A$ condição pós-moderna, que foi publicado pela primeira vez em 1979. Quando Lyotard escreveu esse livro, ele inventou a palavra performatividade, em parte com base no que o filósofo inglês John Austin tinha escrito na década de 1950.

John Austin desenvolveu o conceito de performativo como sendo uma característica da nossa língua. Filósofos anglófonos tendiam a se preocupar com constatações sobre o mundo, como, por exemplo, "0 copo está sobre a mesa". Eles se interessavam em saber como isso opera, qual era a lógica dessa constatação, o que legitimava essa declaração. 0 que Austin diz é que, às vezes, as declarações que são relevantes para nós, as proposições que enunciamos, não estão descrevendo o mundo da mesma forma que "o copo está sobre a mesa" está: elas estão fazendo algo. Então, se eu digo "Prometo vê-lo no centro de São Paulo amanhã às seis”, ao dizer isso, estou fazendo uma promessa. Não estou descrevendo a minha promessa; estou fazendo a promessa.

0 que Austin diz é que essa classe de enunciados, esse tipo de proposição, pode ser classificada como um enunciado performativo, em contraste com um enunciado de constatação, tal como "o copo está sobre a mesa”. Agora, a maneira como Lyotard usou isso é, de certa maneira, muito limitada, porque ele só está interessado em usar a palavra performatividade de modo negativo. Austin não estava falando de coisas boas ou coisas ruins; ele estava apenas descrevendo o funcionamento da linguagem.

0 que Lyotard fez foi dizer que a performatividade é uma característica, uma característica ascendente no nosso mundo. Performatividade tem a ver com a maneira como o sistema em que vivemos procura sempre otimizar o uso do tempo: procura-se tornar tudo mais eficiente pela economia do tempo, mede-se as coisas em termos de entradas e saídas, inclusive a própria economia de tempo. É possível observar esse desenvolvimento quase que inexoravelmente na educação. É frequente agora (pelo menos no mundo anglófono) que a classe seja julgada em termos de seus outputs. Ela é julgada em termos de quantos alunos alcançam determinadas notas. Dessa maneira, as coisas devem ser mensuráveis e contabilizadas de acordo com seu desempenho comportamental. Agora, esse tornou-se um elemento-chave em quase todos os processos de reforma. E é claro que o considero prejudicial 
em muitos aspectos. Não é que eu ache que não deveria haver nenhuma auditoria, nenhuma contabilidade, como já disse antes. Mas acho que, quando a cultura da auditoria se sobrepõe, quando a performatividade domina tudo, isso é bastante desastroso para a educação.

Então, não estou criticando o examinar, a prestação de contas. Estou criticando a ideologia da cultura de auditoria, que diz “precisa ser dessa maneira”. E digo ideologia porque eles tampam os ouvidos: eles não vão ouvir nada além disso, eles não vão ver nada mais. E a parte disso que se relaciona com este artigo é que eles estão dizendo que, se eles não podem ver isso, isso não está lá. Transparência: se não posso ver algo, ele não está lá.

Mas muitas coisas importantes acontecem na sala de aula, as quais você não pode exibir em uma performance comportamental. Claro que dependemos de comportamento, estamos olhando para as reações e os comportamentos uns dos outros agora, nós fazemos isso o tempo todo. Mas é um erro pensar que poderíamos classificar esse comportamento ou reduzir o significado do que está acontecendo a esse comportamento. Portanto, é um erro pensar que as coisas devem ser transparentes.

Relacionado a isso também está o fato de que, nas circunstâncias contemporâneas, as avaliações do PISA têm efeitos de longo alcance. Elas têm normas comuns, um conjunto padrão de critérios que se aplicam aos países ao redor do mundo, e esse padrão suprime tradições locais: isso faz com que eles entrem em uma forma padrão de pensamento obcecada por tabelas de classificação e avaliação. Isso é muito ruim.

0 outro fator, pelo qual vocês são mais afetados do que as pessoas no Reino Unido, é a operação do Banco Mundial, porque o Banco Mundial só apoiará os países que tiverem reformas liberais em andamento, incluindo reformas na educação. E isso exerce, creio eu, uma opressão sobre os países mais pobres. Bem, talvez o Brasil não seja um país mais pobre. Mas tenho certeza que ficou claro o que eu quis dizer.
Nos últimos anos, uma reforma nacional no Brasil reintroduziu a exigência da filosofia (e da sociologia) no currículo escolar. Que potencial você vê para a filosofia em um contexto em que a escola brasileira, depois de superar o desafio do acesso, tenta agora superar o desafio da qualidade do ensino?

Bem, acho que essa pergunta tem duas facetas, dois lados. Acredito que a questão da qualidade do ensino não está necessariamente ligada à existência ou não das disciplinas de filosofia ou sociologia nas escolas. Então, não vejo a filosofia como uma solução para seus problemas. Mas, de maneira geral, sou a favor de ensinar filosofia. Eu invejava países como a França, por exemplo, nos quais ela tem sido parte do currículo. Penso que é uma coisa enriquecedora para as pessoas. Acho, em certo sentido, que a filosofia tem um lugar especial em uma educação realmente ampla. Outros assuntos das humanidades tocam em questões filosóficas, mas é uma experiência enriquecedora ser introduzido a elas de forma mais direta. De modo que parece ser algo desejável, mas não necessariamente ligado à questão geral da qualidade de ensino nas escolas.

Qual a sua opinião sobre o ensino de filosofia para crianças?

Não sou muito a favor de P4C (Philosophy for Children, na sigla em inglês). Em muitos países, incluindo o Reino Unido, a filosofia para crianças tem sido tomada como uma solução para problemas comportamentais ou uma solução para a motivação, ou para ajudar as crianças a serem cidadãs mais responsáveis. Portanto, ela é instrumentalizada e concebida de uma forma muito estereotipada. Os alunos dos quais estamos falando às vezes são crianças bastante novas. Para entender do que estou falando, basta assistir a "Sócrates para crianças de 6 anos" no YouTube. Mas digo que é uma maneira estereotipada porque as crianças se sentam em círculo - o professor 
não diz a elas nada diretamente, não ensina diretamente, mas ele coordena, ele preside a reunião, se você preferir assim -, e, em seguida, sempre que uma criança falar, elas têm que dizer, elas podem dizer qualquer coisa, mas elas têm que dizer "Bem, concordo com o Rafael, mas não concordo com a Rita”. E, em seguida, elas apresentam suas próprias opiniões. Elas precisam sempre fazer isso. Então, há um tipo de estrutura artificial imposta nessa discussão, e ela na verdade prejudica a argumentação. Ela impede a argumentação ao invés de incentivá-la.

Então, desconfio [da P4C], especialmente porque alguns de seus defensores são muito dogmáticos quanto a ela. Eles são como a igreja evangélica: eles estão muito divididos em diferentes facções, de modo que um grupo não concorda com o outro em suas abordagens.

Outra objeção é a seguinte: é claro que existem bons aspectos na $\mathrm{P} 4 \mathrm{C}$, mas muitas vezes são coisas que bons professores já teriam feito mesmo sem ela. Entretanto, seus defensores advogam que essa sua nova abordagem é bastante diferente do que os professores faziam à moda antiga. Então, tenho reservas quanto a essa proposta.

Como já disse, sou a favor da filosofia e da sociologia serem ensinadas nas escolas, mas não as vejo como uma solução para as questões de qualidade do ensino.

Hoje no Brasil, há uma tendência muito forte a reduzir o número de disciplinas teóricas do currículo de pedagogia, substituindo-as por outras de caráter mais prático. Isso já ocorre principalmente em faculdades particulares. As instituições públicas são acusadas de dar uma educação muito teórica para seus alunos e, consequentemente, não prepará-los para a prática profissional. Como você vê as implicações dessas novas diretrizes educacionais para a formação de professores?

Bem, tenho algumas sugestões. Em primeiro lugar, tornamos os alunos cientes das diferentes práticas de ensino, das diferentes maneiras como a educação tem sido entendida, das diferentes prioridades em educação, em parte por meio de conteúdo histórico e também por meio do estudo comparativo e dos tipos de argumentos, justificativas e visões que foram desenvolvidas nesses diferentes contextos. Em termos comparativos, refiro-me, por exemplo, a olhar para algumas práticas budistas. Existe uma forma budista de tiro com arco, que tem códigos de conduta bastante diferentes, bem diferentes da forma como o tiro com arco seria concebido, digamos, nos Jogos Olímpicos. Ou a cerimônia do chá no Japão. Parecem bem estranhos quando vistos de fora, não parecem nada eficientes. Mas ver como as pessoas podem pensar de forma diferente e o significado que pode ser encontrado em práticas que parecem bastante opacas vistas de fora pode ser muito rico para o estudo da educação. Outro bom exemplo é a caligrafia. Mas também gostaria de saber como o homem que vi outro dia tocando saxofone brilhantemente na praia de Ipanema aprendeu a tocar. Com certeza, há tradições de transmissão de música de uma geração a outra que são muito ricas e abrigam formas de ensino e aprendizagem bem elaboradas, mas que são muito diferentes dos métodos oficiais de bom ensino que estão nos livros e documentos que seguem diretrizes educacionais. Então, esses tipos de comparações são formas de perceber o quão diferentes podem ser as boas práticas educacionais. E acho que isso pode ser muito proveitoso.

A segunda coisa é aquilo a que me referi antes: se temos muitos exemplos de pessoas ensinando - tanto explorações fictícias do ensino e aprendizagem, como gravações de vídeo de pessoas em ambientes reais -, então, olhamos para esses exemplos e os discutimos e vemos como as coisas poderiam ser feitas de forma diferente. Acho que isso é algo muito bom de se fazer.

Geralmente, e este é meu terceiro ponto, no ensino e na aprendizagem, deve-se evitar modelos ou princípios teóricos, a menos que nos dirijam a uma compreensão mais sutil e mais 
afınada com a experiência real e com práticas específicas. Deveríamos dar maior ênfase a colocar um caso ao lado do outro e ver suas conexões e diferenças. "Irei ensiná-lo diferenças" - essa é a fala do Rei Lear de Shakespeare que Wittgenstein disse talvez ser o motivo de seu trabalho. "Irei ensiná-lo diferenças."

E, então, um quarto ponto seria a necessidade de reconhecer e atentar ao contexto, adaptando o ensino a ele, porque o contexto varia o tempo todo: ele muda a cada ano com a nova turma, com indivíduos diferentes, conforme as diferentes partes da cidade ou do país ou de acordo com o grupo que você está ensinando, e assim por diante. Ele muda com os momentos de transição e alterações de humor dentro de uma sala de aula. 0 que você ensina em si não é um corpo estático de conhecimento, mas material que convida a novas possibilidades. Você precisa, portanto, ser muito comprometido com o que está fazendo para refletir sobre essas opções. Grande parte desse pensar não vai ser uma espécie de prática reflexiva, mas sim uma questão de pensamento em ação.

E o último ponto é reconhecer o desafio existencial do ensino. 0 que quero dizer com isso é, antes de tudo, que começar a ensinar, principalmente se é para crianças em uma escola, pode ser uma experiência muito inquietante e perturbadora. Por exemplo, se você estiver lecionando em uma escola e um dia usar uma roupa esquisita, a classe muito provavelmente irá zombar de você. $\mathrm{Ou}$, se você tiver uma certa aparência que eles acharem estranha, irão imediatamente lhe dar um apelido. Você se expõe fisicamente diante de pessoas, e essas questões aparentemente triviais, na verdade, são reveladoras de algo mais profundo. Todos olham para você e você tem que desempenhar algum tipo de papel perante eles. Estar diante deles implica que você tem algo que vale a pena ser passado.
Em alguma medida, sua credibilidade se baseia nisso. E talvez você não esteja totalmente confiante quanto a tê-lo, principalmente a transmiti-lo de modo adequado a esses alunos. Isso pode fazer você se sentir muito exposto. Quando você ensina pessoas, muitas vezes isso acontece. E nos afeta de maneiras que não poderíamos ter previsto. Ora se está compenetrado no que se está fazendo com eles, ora se está angustiado com a possibilidade de alguma coisa dar errado. Ou podemos até nos sentir envergonhados se algo der errado. Tudo isso pode nos transformar; isso tem efeito e pode nos mudar como pessoas. E certamente não é uma coisa tão ruim: é o tipo de exposição que ocorre quando alguém testemunha alguma coisa, algo que é importante de alguma forma e precisa ser passado adiante. Em geral, acho que os programas de formação de professores ainda não começaram a reconhecer e refletir sobre a natureza e o significado disso, embora certamente haja alguns formadores de professores cujas ações indicam que eles têm algumas suspeitas do que estou colocando aqui. E, voltando a Platão, acho que ele percebe isso quando apresenta algumas dessas coisas através de Sócrates, isto é, ao não mostrar Sócrates como aquele questionador especialista que auxilia o estudante a resolver seus problemas.

Eu realmente acho que isso é parte do que faz do ensino uma coisa tão profundamente importante na vida humana. Compreender a vida humana da maneira de Wittgenstein: ele quer entender a cena do ensino, o que se passa nessa interação que temos com outras pessoas quando nós apresentamos a elas uma prática, seja na educação escolar formal, seja em casa com filhos ou amigos, seja construindo algo juntos ou indo ao armazém para comprar cinco maçãs vermelhas ou aprendendo a contar uma piada, ou fazendo orações, e muito mais. É uma parte muito profunda de nossas vidas.

\section{Referências}

AUSTIN, John Langshaw. How to do things with words. Oxford: Oxford University Press, 1975. 
GALLIE, Walter Boyce Essentially contested concepts. Proceedings of the Aristotelian Society, v. 56, 1956. New series.

LYOTARD, Jean-François. A condição pós-moderna. Tradução Ricardo Corrêa Barbosa. Rio de Janeiro: José Olympio, 2011.

SCHEFFLER, Israel. Teachers of my youth: an American Jewish experience. Dordrecht: Kluwer Academic Publishers, 1994.

SCHEFFLER, Israel. A linguagem da educação. São Paulo: Edusp: Saraiva, 1968.

STANDISH, Paul. 'THIS is produced by a brain-process!': Wittgenstein, transparency and psychology today. Journal of Philosophy of Education, v. 46, n. 1, p. 60-72, Feb 2012.

WILSON, John. Pensar com conceitos. São Paulo: Martins Fontes, 2005.

WITTGENSTEIN, Ludwig. Philosophical investigations. Translated by ANSCOMBE, Gertrude Elisabeth Margaret. Oxford: Blackwell, 1997.

WITTGENSTEIN, Ludwig. Tractatus Logico-Philosophicus. Traduzido por Luiz Henrique Lopes dos Santos. São Paulo: EDUSP, 1994.

WITTGENSTEIN, Ludwig. Bemerkungen über Frazers “The Golden Bough”. Texto bilíngue alemão - português. Disponível em: <http://www.unicamp.br/ joaojose/observacoes_ramo_de_ouro.pdf>. Acesso em: set. 2015

\section{Publicações selecionadas do autor}

\section{Livros}

STANDISH, Paul. Universities remembering Europe: nations, culture, and higher education. CRAWLEY, Francis; SMEYERS, Paul; STANDISH, Paul (Ed.). Oxford: Berghahn Books, 2000. p. 217-236.

STANDISH, Paul; SMEYERS, Paul; SMITH, Richard. The therapy of education: philosophy, happiness and personal growth. London: Palgrave Macmillan, 2006.

STANDISH, Paul. Beyond the Self: Wittgenstein, Heidegger, Levinas, and the limits of language. Aldershot: Avebury, 1992.

STANDISH, Paul; SAITO, Naoko (Ed.) Education and the Kyoto school of philosophy: pedagogy for human transformation. Berlin: Springer, 2012. (Contemporary philosophies and theories in education; v. 1).

STANDISH, Paul; SAITO, Naoko (Ed.). Stanley cavell and the education of grownups. New York: Fordham University Press, 2012.

\section{Capítulos}

STANDISH, Paul. Levinas and the language of the curriculum. In: EGÉA-KUEHNE, Denise (Ed.). Levinas and education: at the intersection of faith and reason. New York: Routledge, 2008. p. 56-66. (Routledge international studies in the philosophy of education; 18).

STANDISH, Paul. Skepticism, acknowledgement, and the ownership of learning. In: SAITO, Naoko; STANDISH, Paul. Stanley cavell and the education of grownups. New York: Fordham University Press, 2012. p. 73-85.

STANDISH, Paul. The learning pharmacy. In: BIESTA, Gert; EGEA-KUEHNE, Denise (Ed.). Derrida and education. London: Routledge, 2001. p. 77-97.

STANDISH, Paul. The vocabulary of acts: neuroscience, phenomenology, and the mirror neuron. In: SMEYERS, Paulus; DEPAEPE, Mark (Ed.). Educational research: the attraction of psychology. v. 6. Netherlands: Springer, 2013. p. 105-118.

STANDISH, Paul. Why we whould not wpeak of an educational science. In: MARSHALL, Jim; SMEYERS, Paul (Org.). Philosophy and education: accepting Wittgenstein's challenge. v. 6, 1995. p 143-157.

STANDISH, Paul; DHILLON, Pradeep. Jean-François Lyotard: just education in passing [Introduction]. In: DHILLON, Pradeep; STANDISH, Paul (Ed.).Lyotard: just education. London: Routledge, 2000. p. 157-176. 


\section{Artigos}

STANDISH, Paul. Concepciones rivales de la filosofia de la educación. Encounters on Education, v. 8, p.17-27, Fall 2007.

STANDISH, Paul. Europe, continental philosophy and the philosophy of education. Comparative Education, v. 40, n. 4, p. 485-501, 2004.

STANDISH, Paul. Transparency, accountability, and the public role of higher education. In: Educationalfutures, v. 4, n. 4, 2012.

STANDISH, Paul. 'THIS is produced by a brain-process!': Wittgenstein, transparency and psychology today. Journal of Philosophy of Education, 46, 1, p. 60-72, Feb 2012. 
